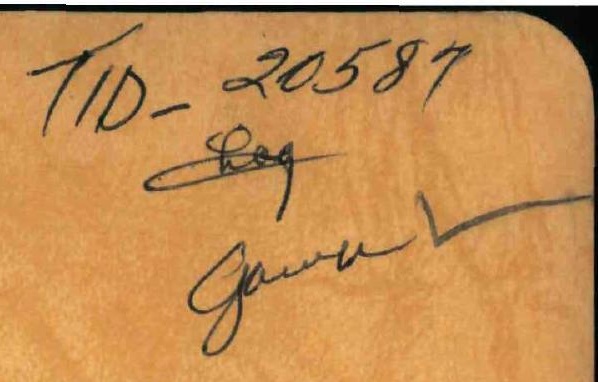

to

U.S. Atomic Energy Commission Chicago Operations office

Lemont, Illinois

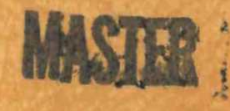

\title{
SODIUM-HEATED STEAM GENERATOR DEVELOPMENT
}

AEC CONTRACT NO. AT $(11-1)-1280$

B\&W CONTRACT NO. 610 - 0067

\section{THE BABCOCK \& WILCO
BOILER DIVISION}

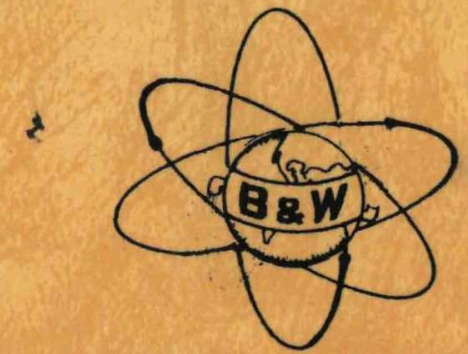

Barberton, Ohio

1

This report has not been cleared for publication. It is sent to the recipient for official governmental purposes only and should not be published or further disseminated until of ficially reviewed and released for pubjication.
Facsimile Price \$

Microfilm Price $\$$

$\frac{5.60}{1.92}$

Available from the

Office of Technical Services

Department of Commerce

Washington 25, D. C.
Q9TENT GLEARANCE OATAINSO. RELEASE TO

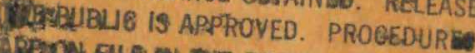

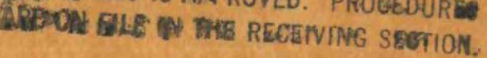




\section{DISCLAIMER}

Portions of this document may be illegible in electronic image products. Images are produced from the best available original document. 
PROGRESS REPORT 5

SEPTEMBER 1963

to

U.S. Atomic Eneryy Commission

Chicago operations office

Lemont, Illinois

AEC Contract No. AT (11-1) - 1280

B\&W Contract No. 610-0067

SODIUM-HEATED STEAM GENERATOR

DEVELOPMENT

signed:CHCHet

Approved:

THE BABCOCK \& WILCOX CO.

BOILER DIVISION

BARBERTON, OHIO 


\section{DISTRIBUTION LIST}

R.B. Abderhalden - Baldwin-Lima-Hamilton Corp.

R.U. Blaser - B\&W Alliance Research Center

T.M. CampbelI - B\&W Alliance Research Center

Dr. K.P. Cohen - General Electric Company

R. Cygan - Atomics International

J.K. Davidson - Allis-Chalmers Manufacturing Company

H.F. Dobe1 - B\&W AED Lynchburg

Dr. T.T. Eggen - Atomics International

Dr。 O.E. Dwyer - USAEC New York

F.M. Heck - Westinghouse Electric Corp.

J. Holliday - USAEC California

W.A. Keilbaugh - B\&W Alliance Research Center

J.V. Levy - USAEC California

R.W. Lockhart - General Electric Company

F.C. MattmueIler - USAEC - Chicago

M.J. McNelly - GeneraI Electric Company

J. Morabito - APDA Michigan

HS Potter - USAEC New York

J.P. Rowe - B\&W Alliance Research Center

W. Savage - ORNL

W.R. Simmons - ANL

G.L. Skinkle - B\&W Chicago Sales

HS Swenson - B\&W Alliance Research Center

S. Visner - Combustion Engineering, Inc.

Dr.G.W.Wensch - USAEC Washington

Dr.R.C.Nerner - MSA Research Corp.

J. Wise - USAEC New York

R. Wykoff - LASL 


\section{TABLE OF CONTENTS}

\section{PAGE}

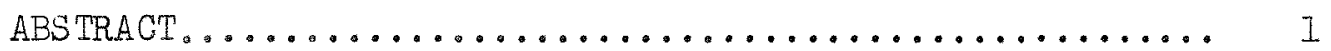

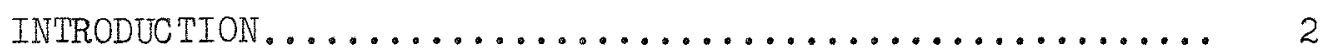

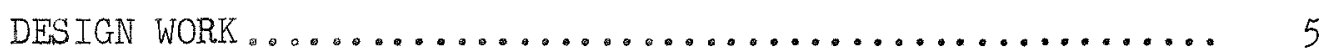

RESEARCH \& DEVELOPMENT PROGRAM................. 18

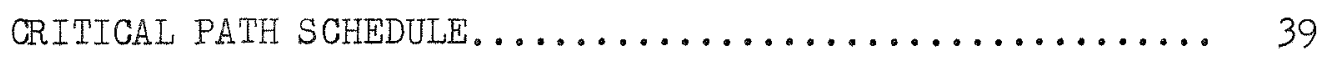




\section{ABSTRACT}

This is the fifth Monthly Progress Report on this Contract. This report contains some information on the history and scope of the Contract and describes the present status of the work.

Phase I of this Contract includes:

Preliminary design of Full-Size Steam Generator Supporting R\&D work

Preliminary design of 30 MWt Prototype Steam Generator

Design work under Phase I is approximately 30 per cent completed.

The Critical Path Schedule shows we have slipped behind schedule as of September 30. By concentrating extra effort on tasks on the critical path during October we plan to get back on schedule. 


\section{INTRODUC TION}

This is the fifth Monthly Progress Report on this Contract. It is planned to include enough background material in each month's progress report that each report can be understood without reference to all previous reports. In general, each report will have a section describing the Design Work, the R\&D program, and the Critical Path Schedule as outlined in the Table of Contents.

\subsection{HISTORY OF CONTRACT}

This Contrgct was received on Mrrch 20, 1963, and signed on April 3, 1963. The overall objective of this Contract is to develop a lorge sodium-heated steam generator of improved design. This steam generator design will be available for use in the Atomic Energy Commission Sodium Reactor Development Program which has the overall objective of developing reliable, economical, large central station nuclear power plants.

\subsection{SCOPE OF CONTRACT}

The scope of work covered under this Contract is briefly as follows:

\section{Phase I}

A - Preliminary design of Full-Size Sodium-Heated Steam Generator.

B - Supporting Research \& Development Work.

G - Preliminary design of 30 MWt Prototype Steam Genergtor. 


\section{Phase II}

A - Detail Design of Prototype Steam Generator.

B - Fabrication of Prototype Steam Generator for Installation and testing at SCTI, Santa Susana, Californis.

C - Final Design Report relating the performance of the Prototype to the design of the Full-Size Steam Generator.

\subsection{CHANGES IN SCOPE OF CONTRACT}

To meet the Commission's overall objective stated above, two changes in the scope of the Contract have been agreed to per F.C. Mattmueller's letters dated May 8 and JuIy 12, 1963. These modifications to the Contract are as follows:

1. The original Contract provided for the design of a 1000 MWt Sodium-Heated steam Generator. This modification now provides that in lieu of a 1000 MWt system design, the Contractor is to design a sodium-heated steam generator system that, together with two identical such systems, will provide sufficient steam for a 1000 MWe plant.

2. The steady-state operating steam pressure at the outlet from the steam genersting system is changed from 2200 to 2400 psig.

The modification to the steam pressure brings the design conditions for these steam generators into agreement with Preferred Standard design conditions for steom turbines, 
and will result in significant savings in steam turbine costs. Economic Evaluation of 600 versus 530 F Feedwater Temperature An economic comparison has been made of the $600 \mathrm{~F}$ feedwater temperature as specified for this Contract with a 530 F feedwater temperature which is typical for a 2400 psi steam power plant employing conventional regenerative feedwater heating. To produce the $600 \mathrm{~F}$ feedwater temperature, a high pressure feedwater heater extracting steam from the high pressure turbine at about $1700 \mathrm{psi}$ would be required. The heater would operate with a steam pressure on the shell side of 1600 psi. The cost of this extra high pressure feedwater heater and the change in cost of other plant equipment was compared to the capitalized fuel cost saving resulting from the higher cycle efficiency possible with the added heater.

This study has shown that with the lowest cost 1600 psi heater available (carbon steel), the costs associated with this extra heater are greater by approximately $\$ 103,000$ than the fuel saving from its use, and therefore the 1600 psi heater cannot be justified economically. The cost difference would be even greater if alloys such as stainless steel or Inconel were used for the heater.

\section{Basis of Comparison}

Two steam turbine cycles were compared, both having $2400 \mathrm{psi}, 1050 \mathrm{~F}$ with $1000 \mathrm{~F}$ reheat. One cycle had eight 
regenerative feedwater heaters to produce a $530 \mathrm{~F}$ feedwater temperature. The other cycle was similar except a ninth heater was added to yield $600 \mathrm{~F}$ feedwater temperature. The change in cycle efficiency was calculated and converted to fuel saving. The following factors were used in evaluating the capitalized fuel cost saving:

1. Fuel Cost $=1.5 \mathrm{mils} / \mathrm{kw}-\mathrm{hr}$

TID 7623 - "Proceedings on Symposium on Sodium Reactor Technology," Lincoln, Nebraska, May 24-25, 1961, pg 172

2. Load Factor $=80 \%$

TID 7025 - "Guide to Nuclear Power Cost Evaluation," Sect. 110, pg 8

3. Capitalization Ratio $=14.5 \%$

TID 7025, Sect. 110, pg 12

The 1600 psi feedwater heater for this plant was designed and its cost was estimated. The change in plant capital cost due to changes in the steam generators, piping, valves, and controls was estimated. The change in plant capital cost was compared to the capitalized fuel saving.

It is realized that this comparison takes into account only economic factors and ignores possible effects of feedwater temperature on reactor transients. Comments on effects of feedwater temperature on reactor operation have been requested.

\section{DESIGN WORK}

The design work under this Contract is proceeding according 
to the Critical Path Schedule included with this report. The status of the design work is as outlined below.

\section{I GENERAL DESCRIPTION OF DESIGN}

To meet the overall Commission objective of developing economical, practical nuclear power, the steam generator being designed under this Contract will be of the "once-through" type because economic studies have shown that the once-through boiler costs considerably less than a recirculating boiler, especially in large sizes. A single tube wall will be used because it is felt that adequate safety measures can be provided to protect personnel and to protect the boiler against severe damage in the event of a tube rupture, and by using a single tube wall a considerable saving in cost results.

A very compact arrangement of heating surface is possible by using concentric helicsl coils for both the boiler and superheater. The steam generator is being designed so that the superheater and boiler tube banks are individually removable for inspection or repair should this be necessary. The boiler bank will be made of a low-cost alloy such as Croloy $21 / 4$ because the tube temperatures are within the use limits for this material. For the high temperature superheater, a material must be used having good stress characteristics at high temperature. Stainless steel and severel other alloys are being investigated for possible application in the superheater. 


\subsection{FULL-SIZE STEAM GENERATORS ( 1000 MWe in 3 units)}

The arrangement of one of the three steam generators required for 1000 MWe is shown on drawing SK 520. Drawings SK 513, 514, and 515 show the shell, boiler bundle, and superheater from which this steam generator is assembled. These three pieces would be frbricated separately and assembled into the complete unit in the field.

By referring to SK 520 one can trace the flow paths of sodium and water through the steam generator. The sodium enters through two 24 -inch sodium inlet nozzles at the top of the steam generator and flows downward through a distributor system that will assure uniform flow across the tubes at the entrance to the superheater and will prevent local high velocity streams from causing vibration difficulties in the superheater. The sodium flows downard in cross flow across the helical coil superheater and continues down across the helical coil boiler bundle leaving the steam generator at one 32-inch sodium outlet nozzle at the bottom. Feedwater enters the steam generator through four water inlet nozzles distributed around the vessel. Only one of the four nozles is shown on the drowing. The feedwater flows downward in tubes arranged in the annular space between the boiler bundle and the shell liner. The feedwater flows to the bottom of the boiler bundle in the downcomer tubes then turns and flows upward through the helical coil boiler bundle where it changes 


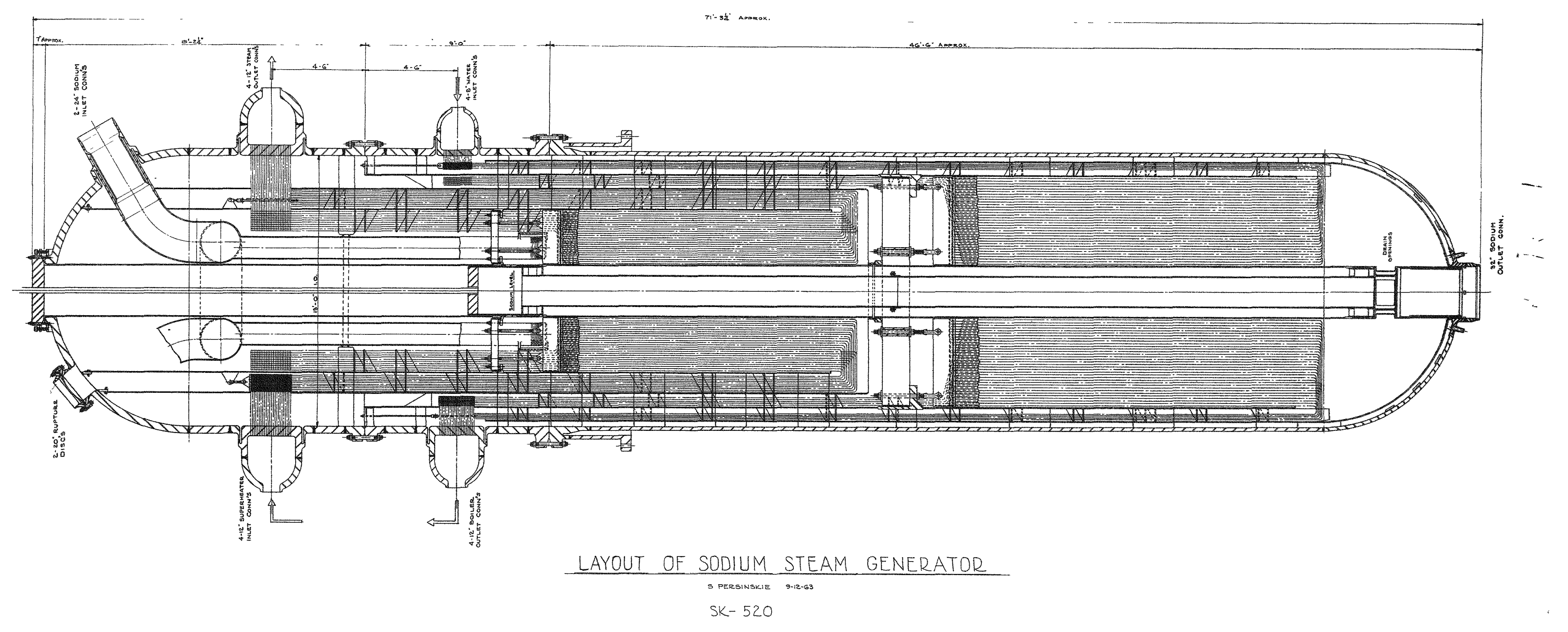




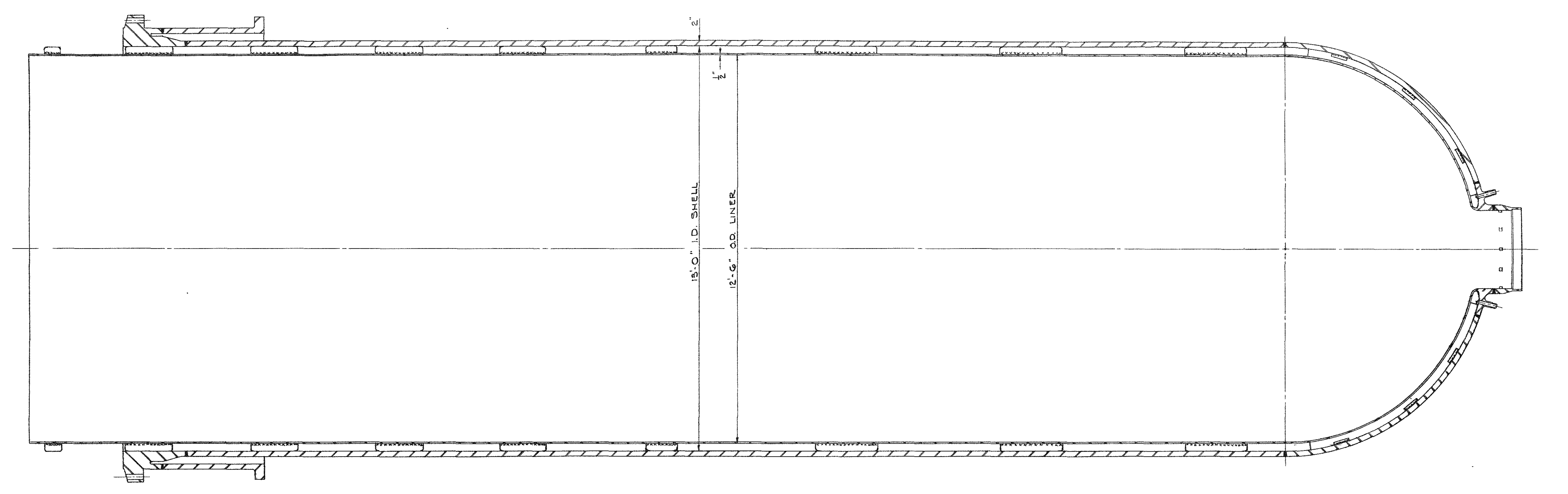

LAYOUT OF SHELL SECTION

$S K-513$ 


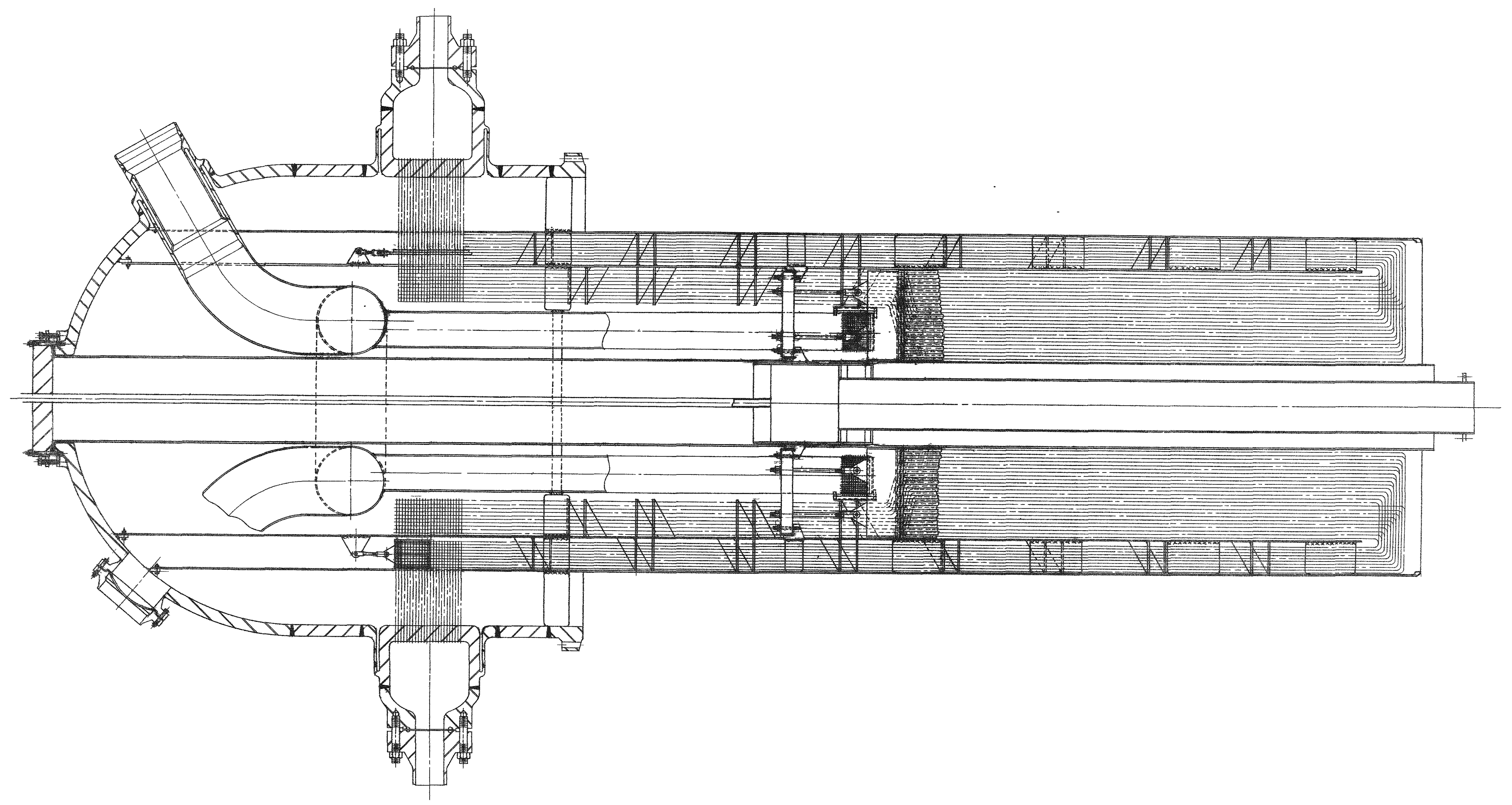

- LAYOUT OF SUPERHEATER SECTION 
to steam and passes upward through the riser tubes to the four boiler outlet tube sheets. The steam flows through innerconnecting piping to the four superheater inlet connections, flows downward through the superheater inlet tubes in the annular space around the superheater, then turns and flows upward through the coil superheater and out through the four superheater outlet nozzles.

Since the boiler is made of Croloy $21 / 4$ and the superheater is made of Type 316 Stainless Steel there must be a dissimilar weld in the piping. This weld will be located outside the boiler where it can be easily inspected. Also, if a leak should occur it will be a leak from the steam to the atmosphere rather than a leak resulting from a sodium-water reaction.

The reheater will be located in a separate vessel, located as close as possible to the steam turbine to save reheat steam piping and pressure drop. The design of the reheater is just beginning. A copy of the first layout drawing will be included in the Progress Report when it is available. Stress analysis caiculations are being made on the first reheater arrangement to determine if flat tube sheets will be feasible. Large flat tube sheets were not feasible for the boiler because of the high pressure, but the reheater operates at only 625 psi so the tube sheets will not have to be as thick as those 
required for the boiler.

Stress analysis work is proceeding on the tube sheets, thermal sleeves, and sodium nozzles of the steam generator. Steady-state thermal stresses are being checked throughout the unit. It appears that locating the tube sheets up in the inert gos spoce obove the sodium level has eliminated any steady-state thermal stress problem on these tube sheets. High thermal gradients were calculated in the cylindrical shrouds surrounding the superheater and boiler bundle. These shrouds are not pressure parts, but do have some of the tube supports attached to them. Gross thermal distortion of these shrouds might cause some of these tube supports to pull Ioose. These shrouds are being modified so each one is made of two cylinders with a small space between. This will spread the thermal gradient out in two cylinders which can move freely with respect to each other and keep thermal stresses and distortion under control.

A study has begun on the feasibility of locating the reheater within the same shell as the boiler and superheater. This integral reheoter design may result in a saving in steam generator cost. Design calculations have been started on optimizing the division of sodium flow and heat transfer surface between the superheater and reheater of this integral rehester design. 
A schematic diagram of the steam generator system is shown on Figure A. This diagram shows one sodium loop, including IHX, boiler, superheater, and reheater. Heot loads, flows, pressures, and temperatures are tabulated at five different loads from 20 per cent to 100 per cent.

It is interesting to note that by the use of a sodium bypass around the superheater and boiler It is possible to maintain steam temperature and reheat temperature at design conditions down to 20 per cent load.

A tabulation of design parameters begins on Page 11. Table 1 describes the boiler, Table 2 the superheater, and Table 3 the reheater. On Page 17 is a plot of pressure drop through various portions of the steam generator at full load, and at 5 per cent over load, and 5 per cent over pressure. Central station steam turbines are customarily designed conservatively so that they can produce additional electrical output if the steam pressure to the turbine is increased 5 per cent. To insure that the steam generator does not limit the maximum capacity of the whole plant, steam generators are usually designed for 5 per cent excess flow and 5 per cent over pressure at the turbine throttle. The design pressures for the various portions of the steam genergtor are set to be slightly higher than the 5 per cent excess flow and 5 per cent over pressure line. This procedure results in what is known as a "stepped" design pressure for 


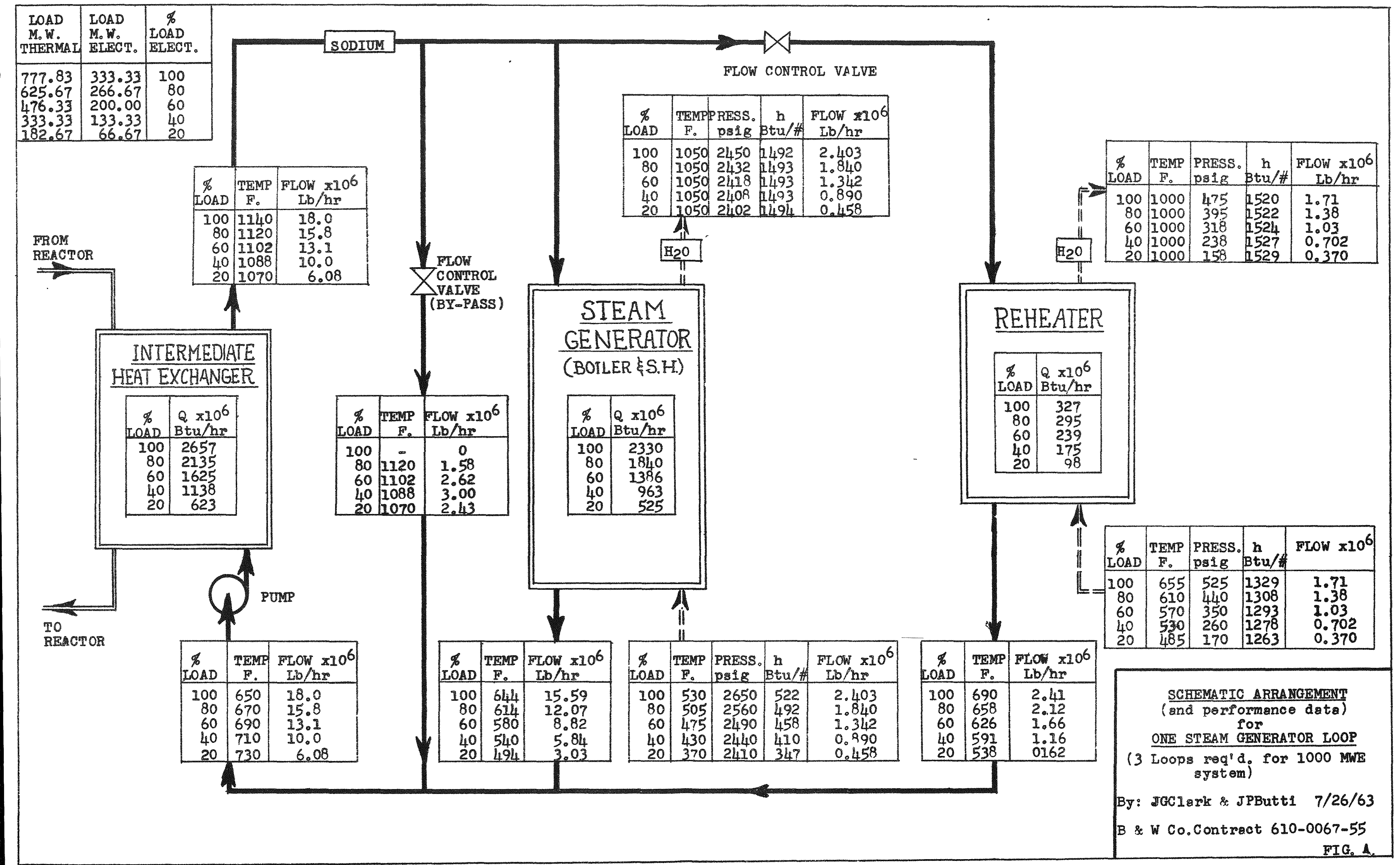




\section{TABLE I}

STEAM GENERATORS

Parameters for one Unit

Three Units Required for 1000 MWe

\section{Design Conditions}

Sodium Temperature

$1200 \mathrm{~F}$

Sodium Pressure

Steam Temperature

300 psi

steam Pressure

$800 \mathrm{~F}$

2725 psi

Operating Conditions (Full Load)

\author{
Heat Load \\ Sodium Elow \\ Sodium Inlet Temperature \\ Sodium Outlet Temperature \\ Sodium Pressure Drop \\ Steam FIow \\ Feedwater Temperature \\ Outlet Temperature \\ Outlet Pressure
}

Material

Tubes

Shells, Heads

Tube Sheets, Noziles
$1736 \times 10^{6} \mathrm{Btu} / \mathrm{hr}$

$15.59 \times 106 \mathrm{lb} / \mathrm{hr}$

$1013 \mathrm{~F}$

$648 \mathrm{~F}$

$1.8 \mathrm{psi}$

$2.403 \times 10^{6} \mathrm{Ib} / \mathrm{hr}$

$530 \mathrm{~F}$

$750 \mathrm{~F}$

2565 psia

Heat Transfer Results

Croloy $2 I / 4, \mathrm{~T}-22$

Croloy $21 / 4$

Croloy $21 / 4$
Number

$\begin{array}{lllll}676 & I^{\prime \prime} & 0 . D \cdot x & .120 " \mathrm{MW} \\ 676 & I^{\prime \prime} & 0 . D \cdot \mathrm{X} & .145^{\prime \prime} \mathrm{MW} \\ 676 & I^{\prime \prime} & 0 . \mathrm{D} \cdot \mathrm{x} & .165^{\prime \prime} \mathrm{MW}\end{array}$

Effective Length

$59 \mathrm{ft}$.

$53 \mathrm{ft}$.

$19 \mathrm{ft}$.

$131 \mathrm{ft}$.

Overall Heat Transfer Coefficient

Economizer

Boller

Nucleate Boiling

Superheater

Film Boiling

Fouling Factor

Corrosion Allowance

$587 \mathrm{~B} / \mathrm{hr} / \mathrm{ft} 2 \mathrm{~F}$ $637 \mathrm{~B} / \mathrm{hr} / \mathrm{ft}^{2} \mathrm{~F}$

$458 \mathrm{~B} / \mathrm{hr} / \mathrm{ft2} \mathrm{F}$ $446 \mathrm{~B} / \mathrm{hr} / \mathrm{ft} 2 \mathrm{~F}$ $3333 \mathrm{~B} / \mathrm{hr} / \mathrm{ft} \mathrm{F}$ 0.009 inches 
Heat Transfer Surface

Tota1

$23,160 \mathrm{ft}^{2}$

Economizer

$\begin{array}{ll}\text { Boiler } & \text { Nucleate Boiling } \\ \text { Superheater } & \text { Film Boiling }\end{array}$

$9,060 \mathrm{ft}^{2}$

$1,330 \mathrm{ft}^{2}$

$9,450 \mathrm{ft}^{2}$

$3,320 \mathrm{ft}^{2}$

Boiler Inlet Tubes

Size

5/8" O.D. X 0.076" MW

Leng th

53 ft.

Boiler Outlet Legs

Size

Length

$1^{\prime \prime}$ O.D. $\times 0.165^{\prime \prime} \mathrm{MN}$

32 ft.

Pressure Drop (Steam Side)

Boiler Inlet Legs

Economizer

Boiler

Nuclear Boiling Section Film Boiling Section

Superheater Section

Outlet Legs

Total

Transverse Tube Spacing $S_{T}$

Parallel Tube Spacing SII
25.50 psi

6.33 psi

$1.20 \mathrm{psi}$

30.80 psi

$20.00 \mathrm{psi}$

$41.00 \mathrm{psi}$

124.83 psi

$1.50^{\prime \prime}$

$1.375^{\prime \prime}$ 


\section{TABLE 2}

\section{SUPERHEATER}

Parameters for One Unit

Three Units Required

for 1000 MWe

\section{Design Conditions}

Sodium Tempergture

$1200 \mathrm{~F}$

Sodium Pressure

$300 \mathrm{psi}$

Steam Tempera ture

$1090 \mathrm{~F}$

Steam Pressure

2675 psi

Operating Conditions (Fuil Load)
Heat Load
Sodium Flow
Sodium Inlet Temperature
Sodium Outlet Temperature
Sodium Pressure Drop
Steam Flow
Steam Inlet Temperature
steam Outlet Temperature
Outlet Pressure

Material

Tube

Shell

Tube sheets, Heads

Heat Transfer Results
Tubes - Number Size
Effective Length
Overa.II H.T. Coefficient
LMTD
Surfiace

Downcomer Inlet Tubes

Size

Material

Length
$594 \times 10^{6} \mathrm{Btu} / \mathrm{hr}$ $15.59 \times 10^{6} \mathrm{lb} / \mathrm{hr}$ $1140 \mathrm{~F}$

$1013 \mathrm{~F}$

$6.7 \mathrm{psi}$

$2.403 \times 10^{6} \mathrm{Ib} / \mathrm{hr}$ $750 \mathrm{~F}$

$1050 \mathrm{~F}$

2465 psia

SA-213 TP 316 SS

Croloy $21 / 4$

TP 316 SS

1220

$7 / 8^{\prime \prime}$ O.D. $\mathrm{x} .120^{\prime \prime} \mathrm{MW}$

$40.6 \mathrm{ft}$.

$358 \mathrm{~B} / \mathrm{hr} / \mathrm{ft}^{2} \mathrm{~F}$

$161.3 \mathrm{~F}$

$11,330 \mathrm{ft}^{2}$

$7 / 8 "$ O.D. $\mathrm{x} \cdot 120^{\prime \prime} \mathrm{MW}$

TP 316 SS

$28 \mathrm{ft}$. 
Outiet Tubes

\section{Size}

Material

Length

Pressure Drop (Steam Side)

Downcomer Tubes

Tube Bundle

Outiet Tubes

Total

Transverse Tube spacing ST

Parallel Tube Spacing S1I
7/8" O.D. X .120" MW

TP 316 SS

$20 \mathrm{ft}$.

15.0 psi

27.5 psi

20.2 psi

62.7 psi

$1.25^{n}$

$1.25^{\prime \prime}$ 
Parameters for One Unit

\section{Design Conditions}

Sodin Temperature

Sodium Pressure

Steam Temperature

Steam Pressure

\section{Operating Conditions (Full Load)}

Heat Load

Sodium Flow

Sodium Iniet Temperature

Sodium Oatlet Temperature

Sodium Pressure Drop (approximately)

Sterm FIow

Steam Inlet Temperature

Steam Outelt Temperature

outlet Pressure

Mater:a1

Tubes

SheII

Tube sheets, Heads

Heat Transfer Results

Tubes - Number Size

Effective Length

Overali H.T. Coefficient

IMTD

Surfoce

Pressure Drop (Steam Side)

Downcomer Tubes

Tube Bundle

Outlet Tubes

Total

Transverse Tube Spacing ST

Parallel Tube Spacing SII
Three Units Required

for 1000 MWe

$1200 \mathrm{~F}$

300 psi

$1050 \mathrm{~F}$

625 psi

$326.7 \times 106 \mathrm{Btu} / \mathrm{hr}$

$2.41 \times 10^{6} \mathrm{lb} / \mathrm{hr}$

$1140 \mathrm{~F}$

$690 \mathrm{~F}$

4 psi

$1.71 \times 10^{6} \mathrm{lb} / \mathrm{hr}$

$655 \mathrm{~F}$

$1000 \mathrm{~F}$

490 psia

SA-213 TP 316 SS

Croloy $21 / 4$

TP $316 \mathrm{SS}$

588

$1 \mathrm{I} / 2^{\prime \prime}$ O.D. X .084" MW

$103.3 \mathrm{ft}$.

$199.7 \mathrm{~B} / \mathrm{hr} / \mathrm{ft}^{2} \mathrm{~F}$

$75.7 \mathrm{~F}$

$23,780 \mathrm{ft}^{2}$

$4.6 \mathrm{psi}$

$16.8 \mathrm{psi}$

$3.7 \mathrm{psi}$

25.1 psi

$2^{11}$

$2^{\prime \prime}$ 
TABLE 3 (CONT'D)

Downcomer Tubes

Size

Length

Outlet Tubes

Size

Length
$11 / 2 " 0 . D * x .084^{\prime \prime} \mathrm{MW}$ $30 \mathrm{ft}$.

$11 / 2^{\prime \prime}$ O.D. X .084" MW $10 \mathrm{ft}$. 
DESIGN PRESSURES

D.C. TO ECON. ECON. BOILER

PRIMARI S.H.

RISERS

I. C. PIPE

SRC. S.H.

PIPE TO TURBINE
2825 PSI

2800 PSI

2725 PSI

2725 PSI

2700 PSI

2675 PSI

2600 PSI

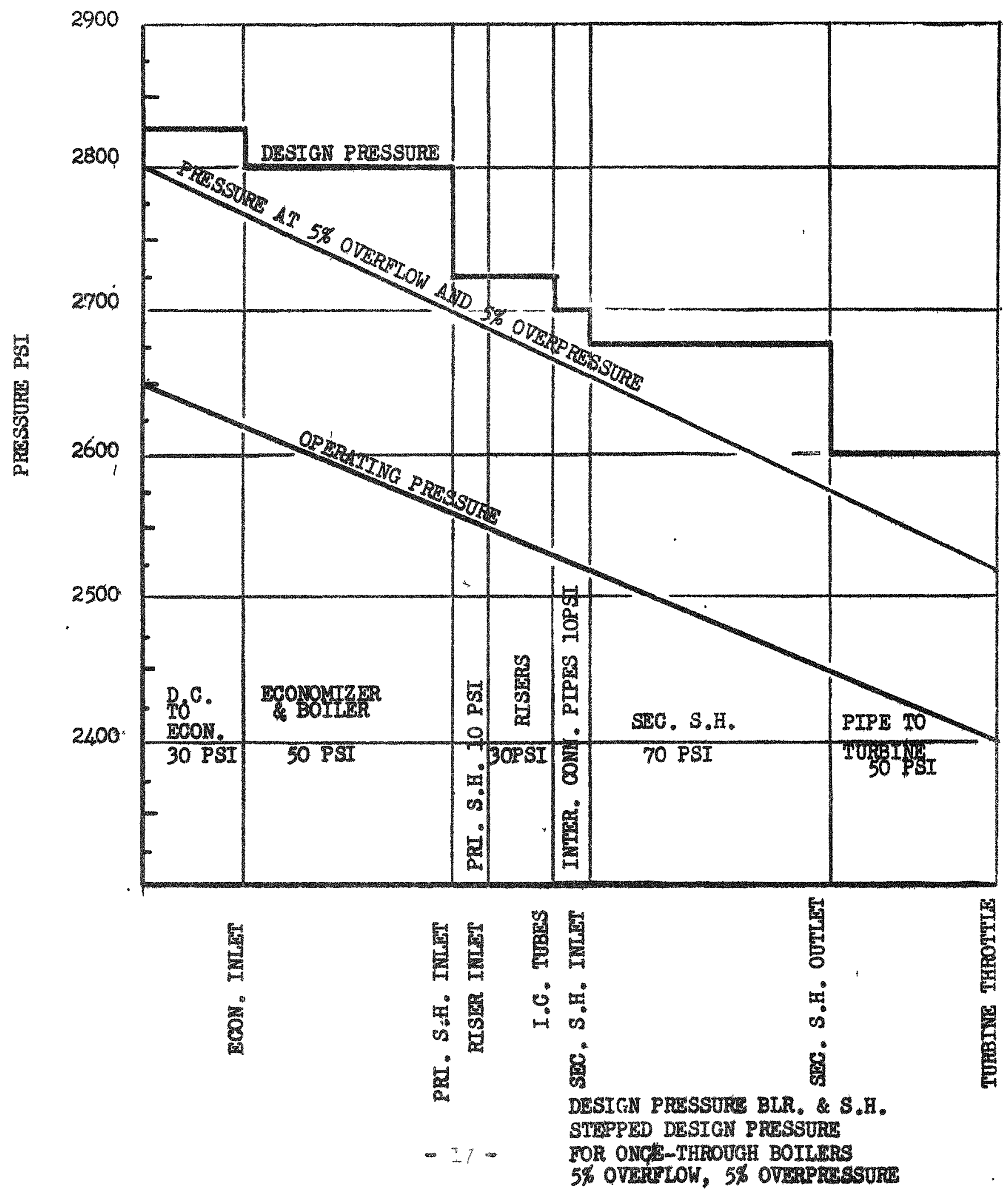


the steam generator. The design pressure for the inlet portions of the steam generator is higher than the design pressure for the outiet. This is a conservative basis for design for a once-through boiler where the safety valves are Iocated at the superheater outlet because the safety valves will IImit the pressure at the superheater outlet and the pressure drop through the steam generator will be lower than the values tabulated at any load below 105 per cent load.

\section{$3.3 \quad 30$ MWT PROTOTYPE STEAM GENERATOR}

Design work on the 30 MWt Prototype Steam Generator has been started to rave a base to work from in trying to model the problems of the Full-size Sterm Genergtor. The heat transfer surface, tube diameters, lengths, etc. have been set and twe tirst layout drawings started. Since the Iayout drawings of the Prototype have not been completed, the proposition drawing SK-057568 is included in this report. This drawing shows the general size and arrongement of the Prototype Steam Generator.

The Prototype will have 27 -inch O.D. tubes in the boiler bank and $557 / 8$-inch O.D. tubes in the superherter. Only one tube sheet and thermal sleeve will be required for each boiler inlet, boiler outlet, SH inlet and SH outlet.

\section{RESEARCH AND DEVELOPMENT PROGRAM}

Research and deveiopment work has been approved under this 


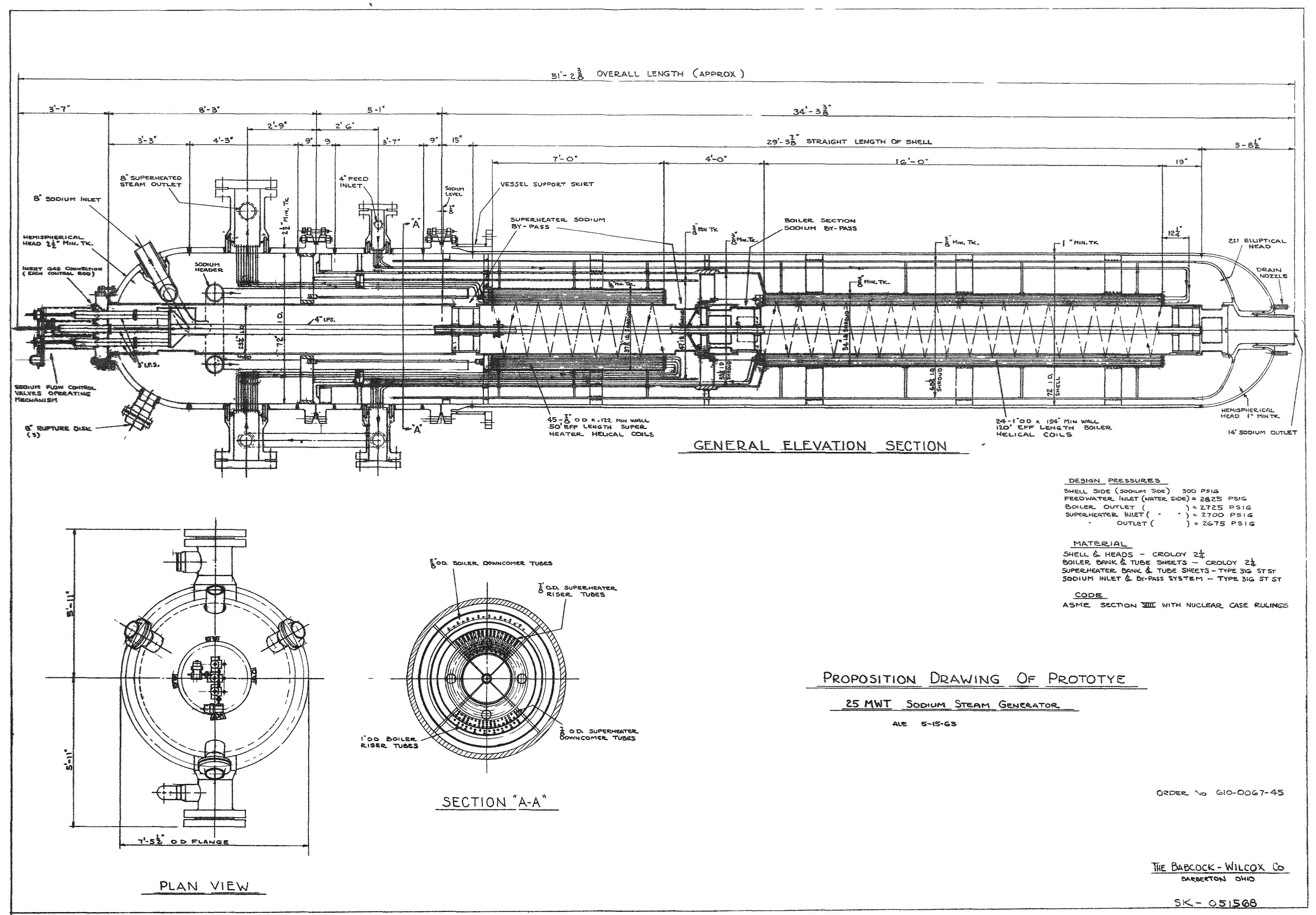


Contract on the following projects:

1. Materials - carbon transfer and effect on material properties.

2. Effect on heat transfer and two-phase flow of coiling tubes.

3. Corrosion of Croloy $21 / 4$ in products of sodium-water reaction.

4. Procedure for welding tube to back side of tube sheet.

5. Radiographic inspection of back side tube welds.

6. Chemical simulation of sodium environment for leak testing.

The problem to be solved and the general scope of each project is described below along with a short description of the present status of each project.

4.1 MATERIALS - carbon transfer and effect on material properties Background Information

There are actue11y two problems relating to meterials and their application for a sodium-heated steam generator. There is the problem of carbon and mass transfer on the sodium side of a tube, and also the problem of possible accelerated corrosion at the location of Departure from Nucleate Boiling on the steam side of the tubes.

It is well known that materials used in sodium systems above $900 \mathrm{~F}$ undergo mass transfer whereby materials are dissolved from the tube walls in the hot zones and deposited in the cooler zones. In addition 
to this, there is a tendency for ferritic materials such as Croloy $21 / 4$ to decarburize in sodium and for the carbon to deposit out on austenitic stainless steel surfaces in the same sodium circuit. Considerable work has been done on mass transfer and carburizationdecarburization problems, but it is evident that further work is required to determine if these problems will be of concern in a closed loop with the relative quantities of Croloy $21 / 4$ and Type 316 Stainless Steel involved in this design.

Tests have shown that accelerated corrosion can occur in boiler tubes at the location of DNB under certain conditions. Under some conditions a boiler tube can fail by corrosion at the DNB point in less than 24 hours. This corrosion is controlled on fossil fuel fired boilers by careful control of water chemistry and by designing the boiler to have the DNB point occur in a $z$ one of low heat flux. The relatively low heat flux at the DNB point comes about becsuse of the necessity of protecting the tube from overheating ("burnout") when nucleate boiling breaks down and film boiling sets in.

In this sodium-heated boiler there are no extremely high temperatures such as are found on the gas side of a fossil fuel fired boiler, but because sodium is so much better a heat transfer medium than gas there can be very 
high heat fluxes with moderate temperature differences between sodium and water.

Tests which have been conducted on model oncethrough sodium-heated steam generators at temperature levels below those for which this boller is being designed showed a small amount of corrosion had taken place. It is felt that further experimentation is required at the temperature levels of interest for this steam generator to be able to say with assurance that serious corrosion will not occur.

\section{Objective}

The purpose of this program is to study the carbon and mass transfer effects in a sodium-heated steam generator containing both austenitic and ferritic materials, and to determine that these materials will be satisfactory on both the sodium and the water side for use under the planned operating conditions.

\section{Scope}

A schematic diagram of the test apparatus is shown on Figure 1. The test boiler will consist of a one-tube model steam generator having a Croloy $21 / 4$ boiler section and a Type 316 Stainless Steel superheater section. The proportion of Croloy $21 / 4$ and stainless steel will be orranged to simulate the proportions of 


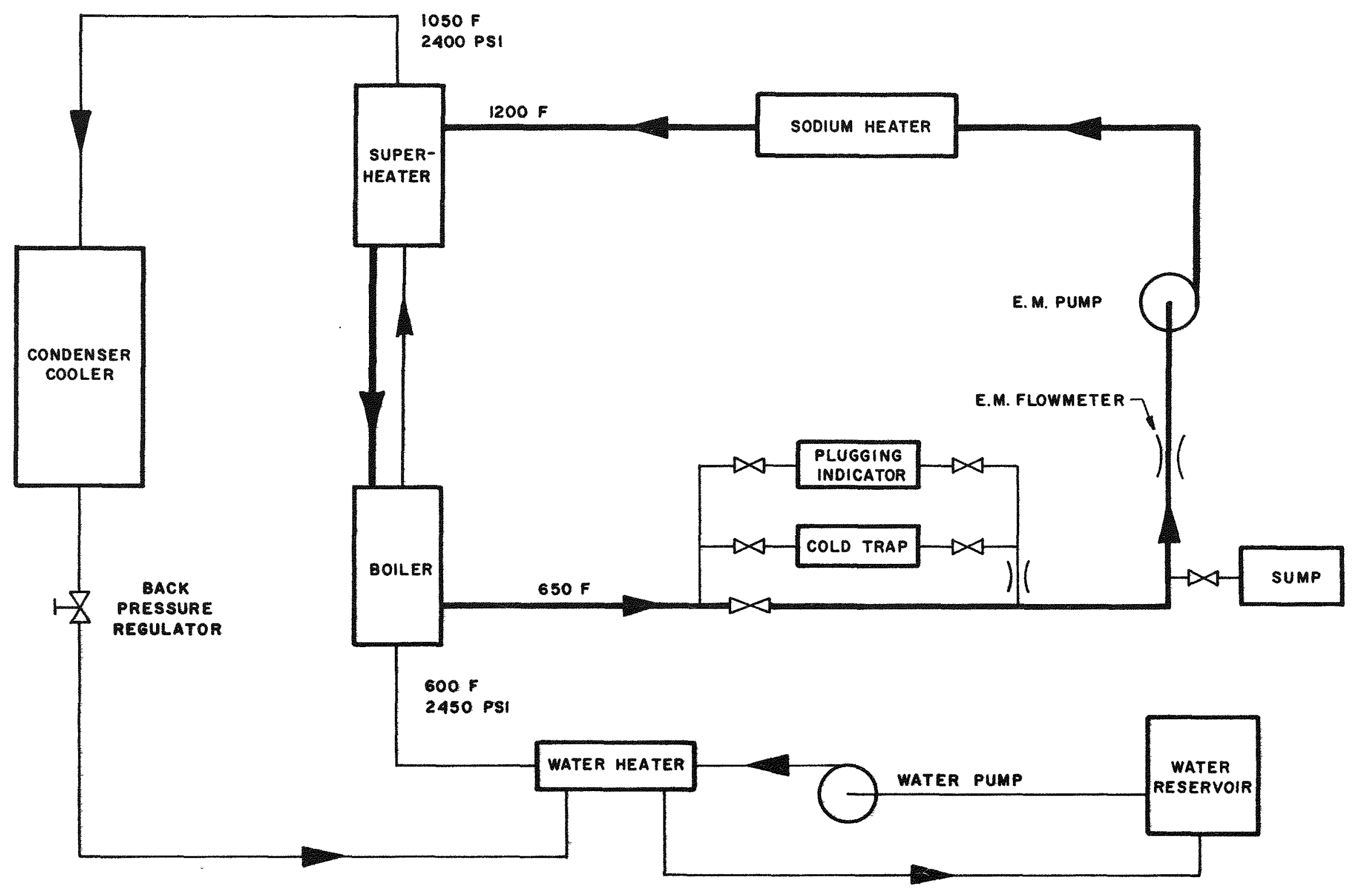

SODIUM HEATED BOILER TEST LOOP

FIGURE I 
these materials in the Full-Size Steam Generator, and the ratio of surfaces exposed to volume of sodium will be made to duplicate the full-size boiler as closely as possible. Sodium will be circulated outside the tube In the model boiler at flow rates and temperatures simulating the full-1oad boiler, and steam will be genergted within the tube at pressures and temperatures similar to the full-1oad boiler. The sodium system consists of an electromagnetic pump, flow meter, sodium heater, plugging indicator, cold trap, and sump. The water-side system includes a reservoir, pump, heater, boiler and superhester, condenser-cooler section, and a back pressure regulator.

In operation, water will be circulated from the reservoir by a recirculating pump into the boiler section at 9 pressure of 2450 psi and $600 \mathrm{~F}$. Steam will ieave the superheater at $2400 \mathrm{psi}$ and $1050 \mathrm{~F}$. The superheated steam is passed through a condensing cooler section, through a back pressure regulator to control the system operating pressure, and back into the reservoir for recirculation.

The sodium system will include the necessary accessory components to provide the required operating conoitions and to maintain any sodium purity.

The test operation will continue for approximately 
one year during which the unit will be subjected to steady-state conditions as well as transient operation. In this way, the full range of anticipated service will be duplicated. Samples will be removed and examined during the test operation to get preliminary test results. Following the test, the unit will be dissembled and the materials examined by appropriate techniques such as metallographic, electron microprobe, electron microscope, and spectrographic means.

\section{Program Schedule}

The following table shows the estimated schedule for the program described above:

\section{Program Schedule}

Design \& Construction

Testing

Analysis \& Report

Total

No. of Weeks
16
52
$\frac{6}{74}$

\section{Present Status}

Functional design of the test apparatus is proceeding. The test section of the model boiler will consist of a double-pipe counterflow heat exchanger with sodium in. the annulus inclined sIightly from the horizontal. Data pertinent to the 1000 MWe steam generating system was received and is being utilized in the design of the model boiler to allow duplication of the more important 
parameters. These include: 1) the tube waIl outside temperature and the temperature difference across the wall, 2) the sodium and the water-steam inlet and outlet temperatures, and 3) the ferritic: austenitic metal surface ratio and metal surface: sodium volume ratio.

The completion of the test program is being withheld until the functional design of the apparatus is finished. In this manner, the design parameters and operating conditions of the test apparatus may be included.

\subsection{EFEECT ON HEAT TRANSFER AND TWO-PHASE FLOW OF COILING TUBES}

Background Information

In any once-through boiler, water enters subcooled and leaves as superheated steam; so somewhere in the boiler, nucleate boiling will break down and film boiling set in. The heat transfer conductance under foilm boiling conditions is much lower than under nucleate boiling so that with a constant sodium temperature outside the tube, the tube wall temperature will increase sharply when film boiling begins. The DNB fluctuates up and down the tube so that a point on the tube wall will see a cycling, boiling conductance and a cycling inner wall temperature. This resulting cycling thermal stress is of concern since it may cause fatigue failures of the tube wall.

In addition to the thermal stress considerations, the amount of heat tronsfer surface area required for a 
boiler will be in error if predictions of the location of DNB and film boiling conductance are in error.

A great amount of work has been done over the past 15 years by the B\&W Company and others on film boiling problems, but all of the prior work has been done on straight tubes. The boiler being designed under this Contract has helical coil tubes to make optimum use of the space available in the cylindrical steam generator vessel.

\section{Objective}

The purpose of this program is to determine the effect of making a tube in a coil configuration on: 1) the location of the Departure from Nucleate Boiling, 2) the nucleate and film boiling heat transfer conductances, and 3) characteristics of two-phase flow.

The results of this program are essential to be able to determine accurately the amount of heat transfer surface required for the steam generator being designed under this contract and to be assured the tubes will not suffer f'atigue or corrosion failures due to temperature fluctuations at the DNB point.

Scope

In this R\&D Program we are fortunate that the test facility is already in existence at B\&W's Alliance 
Research Center. This facility has been in use for a number of years investigating boiling problems, and the operation of the focility and technique for obtaining reliable data have already been proven out.

A schematic diagram of the test facility is shown on Figure 2. It will be noted that there are two separate water loops in this test facility. Each has pumps, flow measuring devices, gnd a flow control valve. One loop flows through the once-through boller to the mixing tee. By adjusting the fow in this loop and the heat input to the gas fired once-through boiler it is possible to obtain steam at various enthalpies entering the mixing tee. The other water loop is unheated and flows directly to the mixing tee. By mixing the flow from these two loops it is possible to adjust the enthalpy of the mixture entering the electrically heated test section over a wide range. This allows independent control of the Iocation of the DNB point in the test section, and the heat input. The versatility of this test facility has proven to be of great value in the study of the DNB probiems and film boiling. The steam leaving the electricaily heated test section passes through throttie valve then is condensed and recirculated through the test focility. A dimenerailzer and deaerator are installed to maintair the purity of the water in 


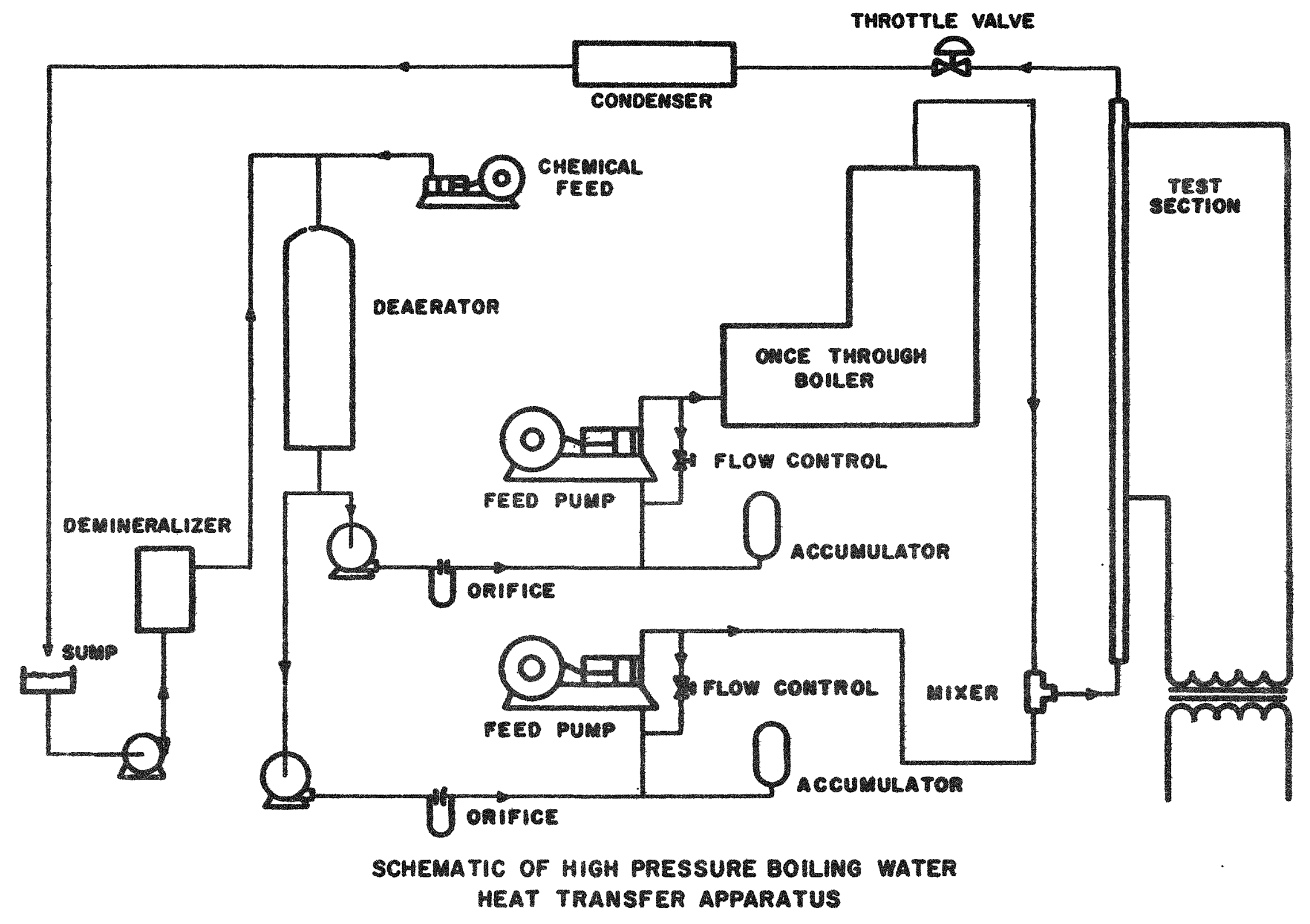


the facility.

For this program, a curved test section will be fabricated and anstalled in this test facility. This test section will be operated over a range of heat fluxes and water velocities simulating the operating conditions of the fuil-size boiler. The test section will be instrumented wi th thermocouples, voltage taps, and pressure taps. The location of the point of DNB will be determined, and the affect on tube temperature recorded. These data will be compared with similar data for straight tubes to determine the effect on boiler design.

Program Schedule

The following table shows the estimated schedule for the proposed program:

Program Schedule

Design \& Construction

Testing

Analysis \& Report
No. of Weeks 16 20

$\frac{16}{52}$

Present Status

Design work is in progress on the curved test section and instrumentation.

\subsection{SODIUM-WATER REACTION}

The program that was originally proposed for investigation 
of sodium-water reaction was concerned only with the ability to relieve the reaction products from a large leak. Experience at Enrico Fermi Station has demonstrated that corrosion in the $z$ one near a relatively small leak is of great concern. A proposal was submitted describing a program approximately as follows:

Small Leak Investigation

1. Corrosion rates for Croloy $21 / 4$ steel in products of a sodium-water reaction.

2. Sma1l leak sodium-water reaction testing in a test vessel containing simulated tube bundle.

Large Leak Testing

1. Theoretical derivations and mathematical model of sodium-water reaction.

2. Large leak testing in test vessel with tube bundle mock-up.

It was proposed that the corrosion test be performed at B\&W Alliance Research Center, and that the other work be subcontracted to APDA. In a letter dated August 26, 1963, Mr. Mattmueller approved the corrosion work to be done at Alliance Research Center and stated that it is the Commission's intention to contract for the remainder of the sodium-water. reaction $R \& D$ work directly with $A P D A$. With this change in 
the scope of the work on sodium-water reaction the R\&D work will be as follows:

Corrosion rates for Croloy $21 / 4$ steel in products of a sodiumwater reaction

Backeround Information

Tube failures, due to sodium-water reactions, can result from stress corrosion cracking, apparent metal fatigue, and bulk transcrystaline corrosion. Considerable interest has been generated in this later type of metal failure, and little is known of its rates under the widely varying environmental conditions which can exist.

Examples of such corrosion can be found in the tube failures at Enrico Fermi Power Plant. In one area where a sodium-water reaction occurred, blisters with longitudinal cracks were noted. The wall thickness of the tube at the point of the reaction was reduced by about $1 / 2$.

With such effects on tubes in a steam generator during a sodiumwater reaction, it is necessary to know as much as possible about this corrosion caused by the products of reaction. This knowledge affects two areas of sodium-heated steam generator design -operation and materials selection.

During normal operation, hot sodium is circulated through the steam generator. If a sodium-water reaction occurs with its associated products of reaction, the 
station operator has two choices in regard to sodium flow, (1) shut off the sodium flow to the steam generator and permit sodium temperature to decay to the isothermal condition, or (2) keep the sodium flowing and maintain a specific temperature in the unit. Since the products and rates of reaction are temperature dependent, it may be advantageous to maintain a predetermined sodium temperature to lessen the corrosion effects of a sodiumwater reaction.

The program described below is directed toward the assembly of the necessary test equipment, and the determination of corrosion rates for Croloy $21 / 4$ steel in hot aqueous solutions of sodium hydroxide, and in suitably equilibrated solutions of sodium hydroxide in molten sodium. Corrosion rates in pure sodium will be determined in order to establish base values for this work,

Groloy $21 / 4$ steel is used for this project since it is more susceptible to gross corrosion in a sodium environment than any of the stainless steels to be used for other parts of the system. Although the austenitic steels are more susceptible to stress corrosion, extensive work has already been done in this area by B\&W and others, This data is available for use in the Sodium-Heated Steam Generator Development Program. 


\section{Objective}

The objective of this program is to provide information pertaining to the rate of corrosion of Croloy $21 / 4$ steel with reaction products of water-to-sodium leak. A second objective is to be able to postulate the mechanism of reaction between Croloy $21 / 4$ steel and the sodium-water reaction products. With such information, it will be possible to determine if there are operational procedures which will reduce the corrosion effect of a sodiumwater reaction on the tube material. Also, the tests will indicate what products of corrosion will affect the tube material and to what extent.

\section{$\underline{\text { Scope }}$}

In a sodium-water reaction, the resulting products are sodium hydroxide, sodium monoxide, and at a temperature less than $800 \mathrm{~F}$-- sodium hydride. The most corrosive compound resulting from this reaction is sodium hydroxide (aqueous). The rates of corrosion of Croloy $21 / 4$ steeI in hot aqueous solutions of sodium hydroxide will be determined. Corrosion products caused by the reaction can exist in almost any concentration. Therefore, the concentrations of sodium hydroxide will be varied from approximately 25 to 98 per cent, and corrosion tests will be made at five different temperatures for each concentration. 
Corrosion tests in these solutions will be made to temperatures as high as their boiling points at atmospheric pressure.

The corrosion testing of sodium hydroxide in sodium will be conducted on Croloy $21 / 4$ at the saturation level at five temperatures varying from 400 to $1500 \mathrm{~F}$. These tests will be made under a dry inert atmosphere. The solution will be stirred to renew the solid-to-liquid innerface. Other tests will be performed with a partial pressure of hydrogen over the sodium-sodium hydroxide solutions to simulate the presence of sodium hydride in the solutions.

In order to have a basis for comparison of the tests, Croloy $21 / 4$ specimens will be subjected to pure molten sodium at the same temperature as those used in the test. Metallographic examinations of the specimens will be performed to ascertain any change which may occur in the grain structure of the metal, as well as the form of metallurgical damage. These specimens will be weighed before and after the corrosion tests are conducted to determine the loss of weight during the test period. The experimental work outIined above will do two things. First, it will establish the effect of sodium hydroxide on Croloy $21 / 4$ steel as a function of concentration and temperature. Since the bulk temperature of the sodium 
In a steam generator can be controlled, operating procedures can be written to minimize the temperature effects of corrosion resulting from a sodium-water reaction.

Second, the amount and nature of corrosion can be determined. With this information, the extent of damage to a boiler tube bundle caused by sodium-water reaction can be estimated, and tube bundle Iife can be predicted.

\section{Program Scheduie}

The time to complete this project will be approximately 56 weeks.

\section{Present Status}

This project has just been approved and work will begin in October.

\subsection{PROCEDURE FOR WELDING TUBES TO BACK SIDE OF TUBE SHEET}

\section{Background Information}

An expanded and seal welded tube-to-tube sheet joint can develop a crevice exposed to the sodium side. Sodium vapor will collect in this crevice. When the steam generator is shut down for maintenance, moisture laden air finding its way into the sodium side of the unit will result in the formation of a strong caustic solution concentrated in the crevice thus presenting the classical conditions for stress corrosion of stainless steel or "caustic embrittlement" of ferritic alloys. 
One way to eliminate the above problem is to machine a projection on the sodium face of the tube sheet at each tube and butt weld the tube to this projection.

The Company has a machine under development for making inexpensive tube-ta-tube sheet butt welds. The development of this welding machine, welding processes, and the quality control procedures will be completed to demonstrate a commercially feasible process for making the tube-to-tube sheet welds on the subject steam generator.

$\underline{\text { Scope }}$

The development work under this program is to complete the development of the welding machine and quality control procedures and demonstrate the ability to produce sound welds in tubes of the sizes and materials used in the boiler being designed under this Contract.

For use with this welding machine, the tube sheets will be machined with projections or lips around each tube hole on the sodium face. A rod with an exponding grip will reach through the tube hole in the tube sheet into the end of the tube. An air cylinder will exert a pull on the rod to draw the end of the tube tightly against the projection on the tube sheet. A carefully controlled current will be passed through the rod and grip to the tube through the lip to the tube sheet and to ground. The resistance where the tube is held against 
the tube sheet will cause heating at this location and the air cylinder will force the tube against the lip and produce a weld. (This general procedure has been used in making tube-to-tube welds in the B\&W shops for a number of years.)

\section{Program Schedule}

It is estimated that this program will be completed in approximately 12 months.

\section{Present Status}

Work on this welding procedure has awaited having design work on the Full-Size Steam Generator far enough to define the location and types of welds, thicknesses, etc. Sufficient layout drawings have been made to define most of the welding considerations. Calculations have begun on the design of a welding mechine to handle all tube sizes, thicknesses, and materials for this boiler.

\subsection{RADIOCRAPHIC INSPECTION OF BACK SIDE OF TUBE WELD}

Background Information

By welding the tube to the back side of the tube sheet, it becomes possible to $x$-ray the weld to prove its integrity whereas an expanded and seal-welded tube-totube sheet joint cannot be $x$-rayed.

The best way to radiograph these welds is to wrap the film around each tube and put a source within the tube 
to radiograph the whole weld at one shot. The alternate method is to take at least two angle shots from outside the tube. A conventional gamma ray source inserted inside the tube gives off its rays from too large a volume to give good definition in the picture. What is needed is a point source of $x$-rays located within the tube.

Scope

This program is to demonstrate the feasibility of constructing a point source for radiographing the tubeto-tube sheet welds.

If a small (1/I6" diameter) sphere of some heavy element is bombarded with electrons, $x$-rays will be produced emanating from this $1 / 16 "$ point. The source of electrons can be a Beta emitter such as Promethium 147. The heavy element target may be surrounded by the Promethium 147 to produce a composite source yielding $x$-rays from a 1/16" diameter point and the whole source will fit within a steam generator tube. Contacts have been made with companies who manufacture radioactive sources and they feel it should be feasible to make such a source.

\section{Program Schedule}

The whole program of demonstrating the feasibility of producing a point source of x-rays and of building a prototype source will take approximately 6 months. 


\section{Present Status}

The actual design of this source will depend on diameters and thicknesses of the tubes for the steam generator which is being designed. Work on the $x$-ray source will be begun as soon as the design work on the steam generator has advanced far enough to set the configuration of the tube ends to be $x$-rayed.

\subsection{GHEMICAL SIMUIATION OF SODIUM ENVIRONMENT FOR LFAK TESTING}

Leaching out of minute slag or oxide inclusions by sodium is well known. Even though metal components are tested by ultrasonics and magnetic particle methods and found to be metallurgically sound, oxide inclusions may still be present. When hot sodium comes in contact with these oxide inclusions, the oxide leaches out leaving areas that are subjected to accelerated attack and ultimate failure.

In a previous sodium-heated boiler proposal, the Company considered shop tests whereby the boiler would be immersed in sodium at operating temperature for approximately three days to leach out any inclusions. The boiler would then be subjected to a mass spectrometer test and any leaks repaired before shipment. However, the many problems associated with handling sodium in a mamufacturing facility, together with the problems of cleaning the sodium from the boiler after the test to prevent the absorption of water from the air and possible setting up of stress corrosion, makes this test 
undesirable.

Recent studies have indicated that it may be possible to find a solution that will react in the same manner as sodium In leaching out oxide but will be easier to handle in a manufacturing facility.

The program to find a suitable reagent to leach out oxide inclusions in Croloy $21 / 4$ and Type 316 Stainless Steel will proceed in the following two phases: Phase I - Feasibility of various reagents for removing oxides:

The two reagents that appear attractive at this time are EDTA (Ethylene Diamine Tetracetic Acid) and Sulfamic Acid. It is planned to do rough-screening testing of the ability of these reagents to remove oxides from Croloy $21 / 4$ and stainless steel material.

Weld deposits on Croloy $21 / 4$ and Type 316 Stainless Steel flat plate will be made under inert atmosphere. No fluxing material will be used. The weld beads will consist of oxides of elements present in the flat plate material. In addition to these, beads of molten slag will be deposited on fal plate specimens. Several different fluxes will be used to produce slags of different characteristics. The ease of removal of the oxides in the beads by either EDTA or Sulfamic Acid will be determined. EDTA is more effective at higher temperatures, so the tests will be conducted at temperatures approaching the breakdown temperature 
of EDTA (approximately 350 F). Semi-quantitative evaluation will be made by visual and low-power magnification (10x) study of the test specimens after treating with the solutions.

\section{Phase II}

If either of these two reagents appear feasible for this application, test specimens can be made up with known oxide inclusions and more exacting techniques used in evaluating the effectiveness of these solutions.

\section{CRITICAL PATH SCHEDUIE}

One of the requirements of this Contract is to schedule the work according to a PERT schedule or equivalent.

A Critical Path Schedule has been prepared for the design work of Phase I. (This is the preliminary design of the FullSize Unit and preliminary design of the 30 MWt Prototype.) The schedule will be expanded to include the R\&D work as soon as the various projects are laid out in enough detail. The schedule for Phase II (detail drawings, procurement of materiels, fabrication and delivery of the 30 MWt Prototype) will be added as soon as possible to facilitate the Commission's planning for SCTI.

In preparing the portion of the schedule for Phase I, the design work was broken down into individual tasks and an arrow diagram made showing the inter-relation of these tasks. The time to complete each task was estimated. In general, the

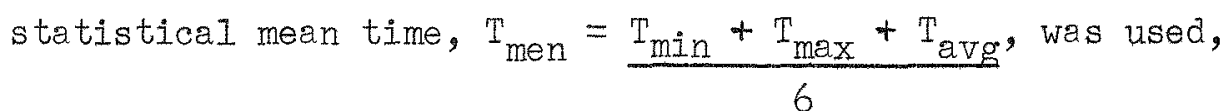


although this was modified in some cases based on experience.

The schedule and times were run on a Critical Path Method program on the Burroughs 220 Computer. This program developed the Critical Path Schedule that was plotted with a time scale as the ordinate to portray the schedule as clearly as possible.

In Report \#1, June 1, 1963, a complete Critical Path Program Chart of the design phase of the full-size vessel and its prototype was included. To assist the reader, the physical length of this chart has been shortened to a double-page size that shows the portion of the up-to-date chart pertinent to the present report. Periodically the full chart will be included in the Monthly Progress Report.

The critical path can be recognized easily as the dark line, and tasks along this line set the overall time span for the whole project. Other tasks have "float" time - shown as dotted Iines. These tasks can float over a considerable time period to make optimum use of manpower without affecting the completion of the overall project. A wavy line above the regular task arrows indicates the progress of the task in relation to the calendar times found at the bottom of the chart.

A short vertical line in front of the wavy line indicates the task started, and two short vertical lines at the end of the wavy Iine indicate the task finished. Delayed starts are possible for all tasks which have "float" time and are not on the critical path. If a task on the critical path is started late and not 
finished on time the whole project may be delayed.

By comparing the status of each task with the large arrow indicating the date of this report it can easily be seen if the task is ahead, on, or behind schedule.

This schedule chart will be brought up to date each month and included in each month's progress report.

\section{Present Status}

By referring to the schedule chart it will be noticed that slippage is showing up along the critical path. On September 30 work had not been started on Sodium Outlet Nozzle Pressure Discontinuity Analysis, Task $92-122$ on the schedule. If this slippage were allowed to continue it will delay the whole job. Extra effort will be put on this task in October to bring the job back on schedule.

This slippage points out what a powerful tool Critical Path scheduling is. The monitoring program being used with the Critical Path Method computer program gives early warning of slippage in the schedule and indicates where we can concentrate our effort to get back on schedule. We are approximately 30 per cent complete on Phase I of this Contract. 


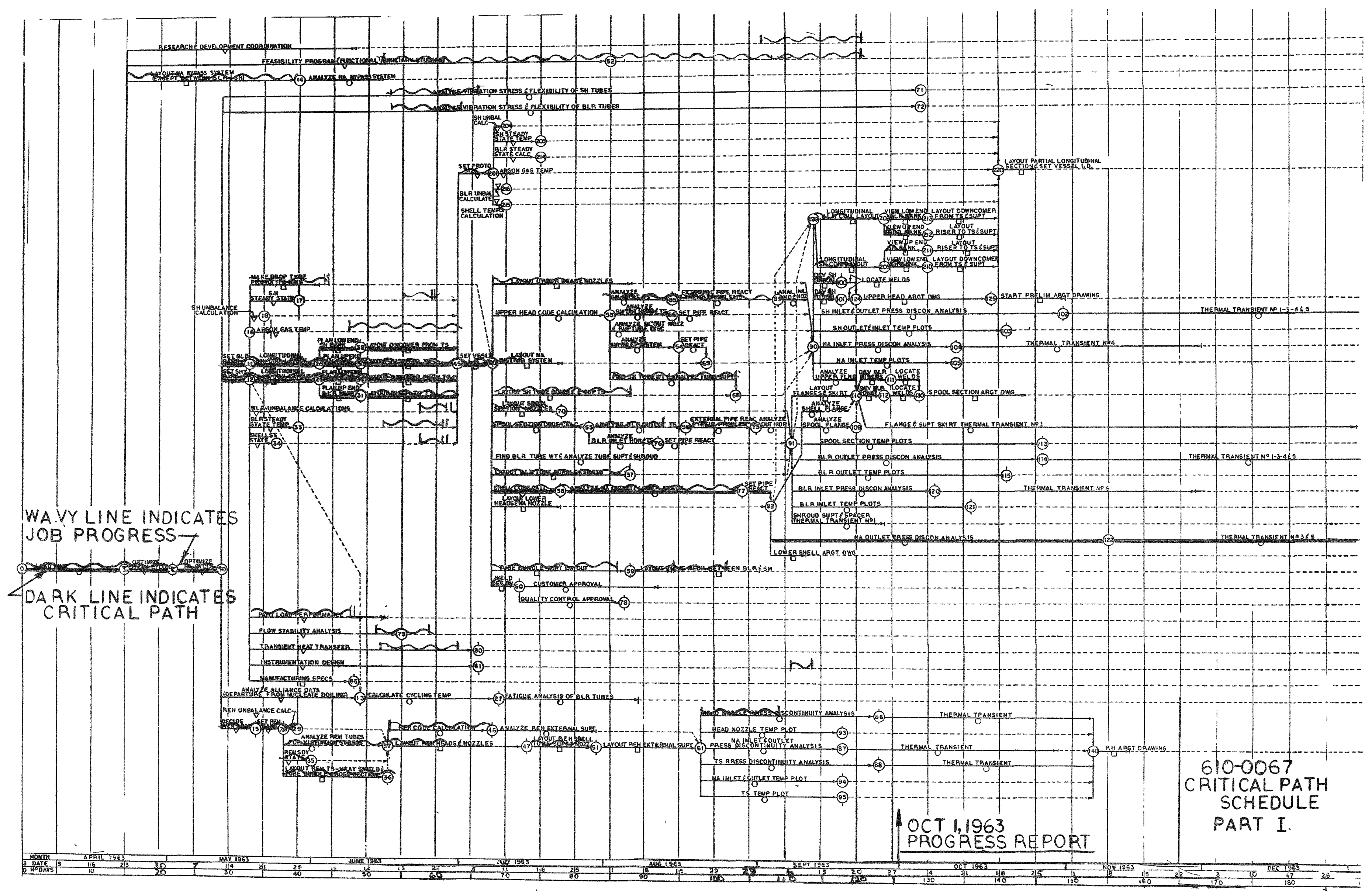

